\title{
A Simple Method to Evaluate the Vapor Pressure of Transformer Oil at
}

\section{Various Temperatures}

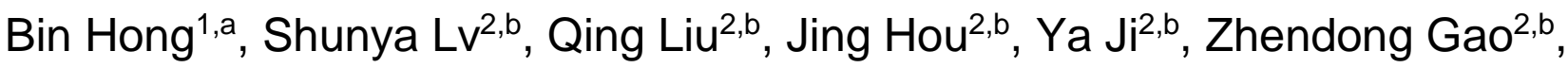 \\ Jianye $\mathrm{GaO}^{2, \mathrm{~b}}$, Ju Hu $\mathrm{Hu}^{2, \mathrm{~b}}$
}

${ }^{1}$ Internal Combustion Engine Research Institute,Tianjin University, Tianjin 300072, China

${ }^{2}$ Tianbo Science \& Technology Co. Ltd., Tianjin 300072, China

atianbohb@126.com, btianbojy905@126.com

Keywords: transformer oil; vapor pressure; thermal balance; experiment data correlation.

Abstract:Transformer oil as an important mineral oil is widely used in power equipments and its fundamental properties can be obviously presented by the vapor pressure which is difficult to be accurately evaluated due to its complex compounds. According to the testing mechanism of thermal balance, a simple method is proposed to evaluate the vapor pressure of transformer oil at various temperatures. The thermal stability and chemical components of the tested oil are characterized and discussed. The experiment data correlation to the vapor pressure of transformer oil is further performed by the typical Clausius-Clapeyron equation. It reveals that the vapor pressure of transformer oil is positively related to temperature environment. Moreover, a deep comparison between the experiment data and the correlated result confirms that the applied evaluating method is a suitable way to evaluate the vapor pressure of transformer oil and other liquid compounds system.

\section{Introduction}

The industrial revolution and increased population in the last two centuries have resulted in an increased consumption of fossil fuels [1]. For over 100 years, petroleum-based mineral oils have been used in liquid-filled electrical transformers. Large amounts of mineral oil are used in electrical equipments as insulation and cooling medium [2,3], which are complex mixtures of linear saturated hydrocarbons (paraffins), cyclic saturated hydrocarbons (naphthenes), aromatic hydrocarbons and a small fraction of non-hydrocarbons, with hundreds of individual compounds [4].

Transformer oil is a derivative of petroleum crude which serves both an insulating and heat [5]. In extra high voltage power equipments, the oil-filled power transformers account for more than $90 \%$ of all transformers [6]. The transformer oil suffers from continuous deterioration and degradation due to electric and cyclic thermal stresses because of the loading and the climatic conditions which may affect the performances and life of the electrical transformer [7]. To avoid damages and cut-off of power electricity supply it is necessary to evaluate the mineral oil condition [2]. Vapor pressure is a fundamental physicochemical property indispensable for many important studies and applications [8-10]. Knowledge of this parameter is crucially important for a wide variety of materials because it is used as a basis to calculate the acentric factor, surface tension, enthalpy of vaporization, thermal and equilibrium properties [11-13]. For example, a change in fuel vapor pressure may results in significant changes in the fuel atomization, evaporation rates, combustions and emission formation processes in numerical simulations [14]. 
The accurate determination of vapor pressures, however, is not an easy task, in particular in the low-pressure region and literature data coming from different authors often shows a significant scatter and/or are influenced by systematic errors [8]. Referencing the simple organic composition system, there are several methods for measuring vapor pressure described in the literature. Differential thermal analysis (DTA) instrumentation with the thermocouple-inserted glass capillary configuration is ideally suited for measurement of boiling points at a variety of pressures [15-17]. Based on the similar testing mechanism, a recently developed thermo-gravimetric analysis (TGA) method is partly applied to provide a rapid means of quantifying vapor pressure of selected organic compounds [18]. Although the mentioned DTA method and TGA method can measure the vapor pressure for transformer oil easily, they are terribly limited by their testing pressure which is infeasible in the low temperature environment. Measurements of vapor pressures by transpiration method have been proposed in a substantial broader temperature ranges with a good experimental condition of saturation by variation of flow rates of the carrier gas [19]. Gas chromatography is another approach used to quickly estimate the vapor pressure of volatile organic compounds [9]. Moreover, some researchers have used different vapor pressures correlations to estimate parameters in equations of state [20,21]. Numerous empirical vapor-pressure equations have been published, the best known are those of Wagner, Lee-Kesler and Ambrose-Walton general models, Clausius, Antoine, Frost-Kalkwarf, Cox, Gomez-Thodos, Riedel Lemmon-Goodwinand Sanjari et al [22,23].

The above methods for measuring the vapor pressure of liquid organic composites are generally available for the pure component or those separable mixture systems which the chemical constants can be provided by the present researches. However, it is well known that petroleum-based transformer oils used in transformers have a diverse and large number of compounds which consists of complex blends of more than 3000 hydrocarbons [24]. It is not practical, indeed it may be impossible, to perform a complete component analysis to such systems [25].To overcome the mentioned testing deficiency and provide the detailed fundamental data for engineering fields, the vapor pressure of transformer oil was measured at various pressures by a constructed apparatus. The thermal stability and chemical structure of the tested transformer oil were characterized considering of the effects of thermal decomposition and aging during the testing process. Furthermore, the experiment data were correlated by the typical Clausius-Clapeyron equation and the vapor pressure measured at low temperature was regressively calculated.

\section{Experimental Section}

\section{Experimental Apparatus}

According to testing principle of the TGA method and DTA method, the vapor pressure data of transformer oil was measured by the constructed apparatus using a thermal balance [26]. The measuring apparatus which is well sealed during the whole testing process is schematically shown in Figures. 1. It includes a vacuum chamber with temperature controller used to heat the testing oil at a wide temperature religion of $25^{\circ} \mathrm{C}$ to $200^{\circ} \mathrm{C}$, a light inside and a camera setting on the vacuum chamber installing to observe the boiling status of transformer oil, a vacuum pump and a pressure control system introducing to adjust the testing pressure at a large pressure range of $50 \mathrm{~Pa}$ to normal atmospheric pressure. With several layers of seal assemblies, the measuring apparatus can accurately control the testing temperature and the vacuum pressure during the whole determination process. 


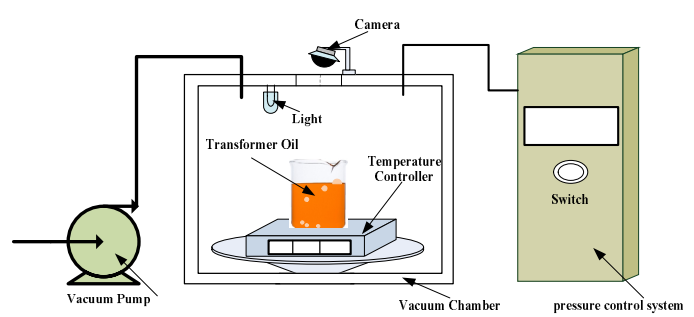

Fig.1 Schematic diagram of the constructed vapor pressure measuring apparatus for transformer oil

\section{Testing Process}

The vapor pressure of transformer oil was measured by the mentioned experimental apparatus. After the air impermeability testing, the transformer oil was initially placed inside the vacuum chamber which was continually heated to the testing temperature. When the transformer oil reached the set temperature stably, turned on the vacuum pump and the oil was kept vacuuming until it boiled violently. As the tested transformer oil reached the boiling point, it is assumed that liquid-vapor equilibrium is established inside the sealed chamber [27]. In other word, it was deemed that the related vacuum pressure was the saturated vapor pressure at this testing temperature. Therefore, the temperature, the vacuum pressure and the testing time were recorded. Moreover, 2 $\mathrm{ml}$ tested oil was collected as the experiment sample for its chemical characterization. Consideration of the actual degassing temperature and working temperature of power transformer insulation, the testing temperature rang was set from $40^{\circ} \mathrm{C}$ to $150^{\circ} \mathrm{C}$.

\section{Characterization}

The thermal stability of the transformer oil was analyzed by TG 209 F3 where the transformer oil was heated from $25^{\circ} \mathrm{C}$ to $400^{\circ} \mathrm{C}$ with a stable $\mathrm{N}_{2}$ atmosphere. The heating rate was set at $10^{\circ} \mathrm{C} / \mathrm{min}$. The fourier transform infrared spectra (FTIR) of the transformer oil was recorded in the range of $4000-400 \mathrm{~cm}^{-1}$ on a Bruker Vertex FT-IR spectrometer. $\mathrm{KBr}$ was chosen as the background and the testing sample was prepared by adding the oil to $\mathrm{KBr}$ with a soaking operation for one minute.

\section{Results and discussion}

\section{Chemical analysis of transformer oil}

During the vapor pressure testing process, the transformer oil may be thermal decomposed which will limit the practical application of the proposed vapor pressure measuring method. Therefore, the thermal analysis and the chemical composition analysis are performed and relevant results are exhibited.

The thermal stability of the transformer oil is shown in Fig.2. From this figure, it can be seen that the quality loss of the transformer oil occurs when the temperature is raised to $80{ }^{\circ} \mathrm{C}$ under the normal pressure. According to the obtained TG curve in Fig.2, the loss rate of the transformer oil is gradually increased accompanied with temperature rise. When temperature increased to $235{ }^{\circ} \mathrm{C}$, transformer oil is volatilized completely which means that the transformer oil is volatilized. From the DTA curve of transformer oil, there is a gradual heat absorption peak deemed as the volatile heat that can be observed at the range of $80 \sim 235{ }^{\circ} \mathrm{C}$ without any other decomposition peaks. This indicates that the transformer oil may be a mineral oil whose components can volatize at similar temperature and the oil did not be decomposed during the thermal analysis process. 


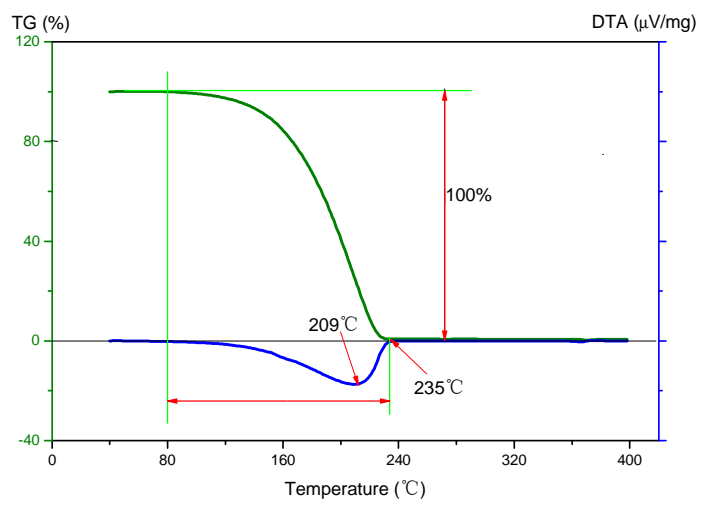

Fig. 2 The thermal analysis results of transformer oil in the normal atmosphere

In order to a further research about its volatilization and decomposition, the chemical composition of transformer oil was analyzed by FTIR measurements. The testing samples were prepared when the oil kept the boiling state for 10 min (named $\mathrm{t}_{1}$ ) and $2 \mathrm{~h}$ (named $\mathrm{t}_{2}$ ), respectively. As shown in Fig.3, there are four strong peaks observed at $2932 \mathrm{~cm}^{-1}, 2859 \mathrm{~cm}^{-1}, 1454 \mathrm{~cm}^{-1}$ and $1372 \mathrm{~cm}^{-1}$ which are assigned to $-\mathrm{CH}_{3}$ and $-\mathrm{CH}_{2}$ - stretching vibrations, implies that the transformer oil is mainly consisted of alkanes compounds. The two weak peaks exhibited at 3650 and 3185 are attributed to the $-\mathrm{OH}$ stretching vibration and other two weak peaks at $2729 \mathrm{~cm}^{-1}$ and $2623 \mathrm{~cm}^{-1}$ represents the $\mathrm{C}-\mathrm{H}$ vibration of aldehydes. The weak peaks at $1609 \mathrm{~cm}^{-1}$ and $1156 \mathrm{~cm}^{-1}$ are caused by $\mathrm{C}=\mathrm{O}$ absorption and the saturated acyl groups. The other weak peak at $732 \mathrm{~cm}^{-1}$ is corresponded to the wagging vibration. The above discussion indicates that the FTIR spectrum of the tested oil is according with the normal transformer oil. From Fig.3, it also can be found that there are obvious reducing tendency when the oil is vacuumed for longer time, which means that the transformer oil volatized during the vapor pressure measurement. However, although distinct volatilization has been observed, there are no new peaks appeared on the FTIR spectrum, revealing that the transformer oil did not distinctly aged and no redox reactions were happened during the testing process. In other words, it demonstrates that the proposed vapor pressure testing method is available to measure the vapor pressure of transformer oil without any side reactions.

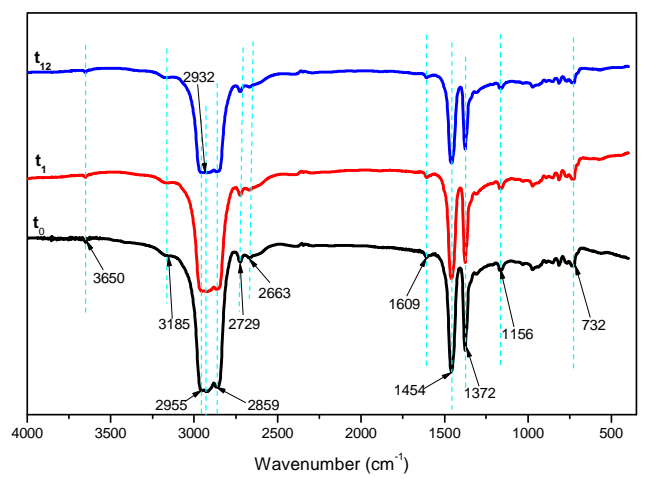

Fig.3 FT-IR spectrums of transformer oil $\left(\mathrm{t}_{0}\right)$ and those kept boiling for $10 \mathrm{~min}\left(\mathrm{t}_{1}\right)$ and $2 \mathrm{~h}\left(\mathrm{t}_{2}\right)$

\section{Experiment data of transformer oil}

The experimental data of transformer oil is summarized in table 1. It is clearly observed that the vapor pressure increases from $160 \mathrm{~Pa}$ to $940 \mathrm{~Pa}$ as the temperature is enlarged from $40{ }^{\circ} \mathrm{C}$ to $150{ }^{\circ} \mathrm{C}$ which preliminarily indicates that the vapor pressure of transformer oil is positively related to the applied temperature. This result is according with the present approved relationship between 
the vapor pressure and the temperature which means that the proposed vapor pressure testing method is available and the experimental data are effective. Based on the testing results, the vapor pressure-temperature relation curve is drawn as shown in Fig.4. Obviously, the vapor pressure of the transformer oil is seriously influenced by the applied temperature. Furthermore, it can be found that the vapor pressure is distinctly increased when the temperature is above $100{ }^{\circ} \mathrm{C}$ while it slightly changed when the temperature is below $100{ }^{\circ} \mathrm{C}$. It can be inferred that a non-negligible error is generated when the testing temperature is below $100{ }^{\circ} \mathrm{C}$ by using the adoptive vapor pressure measuring method. Therefore, the evaluation of the vapor pressure in a lower temperature is invalid only by the experiment test and a followed data correlation analysis is extremely essential for transformer oil.

Table 1. Experimental Data on Vapor Pressure of transformer oil

\begin{tabular}{|c|c|}
\hline Temperature $\left[\mathrm{T} /{ }^{\circ} \mathrm{C}\right]$ & Vapor Pressure $[\mathrm{P} / \mathrm{Pa}]$ \\
\hline 40 & 160 \\
\hline 50 & 185 \\
\hline 60 & 170 \\
\hline 70 & 165 \\
\hline 80 & 215 \\
\hline 90 & 245 \\
\hline 100 & 245 \\
\hline 110 & 325 \\
\hline 120 & 470 \\
\hline 130 & 600 \\
\hline 140 & 770 \\
\hline 150 & 940 \\
\hline
\end{tabular}

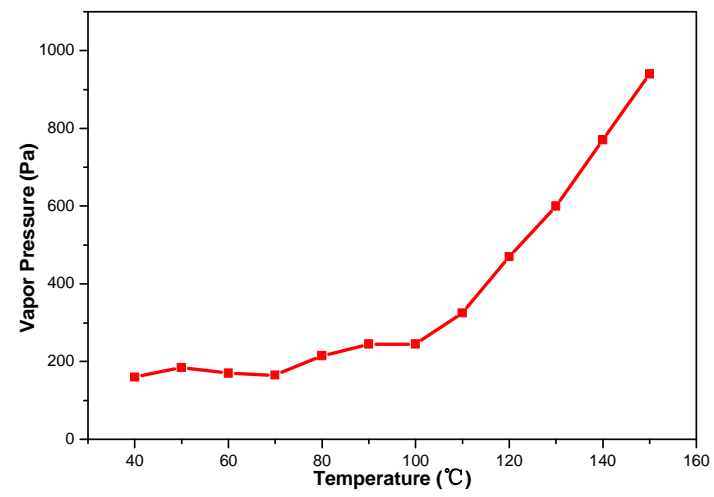

Fig.4 The relation curve of the measured vapor pressure and its related temperature

\section{Experiment data correlation for transformer oil}

Based on the above experiment data and discussion, the vapor pressure of transformer oil in a lower temperature environment is high-error which is limited by the measuring apparatus. Therefore, the data correlation is necessary to fit the vapor pressure data by the tested correlating vapor pressure equations. Theoretically, the vapor pressure is regularly related with temperature, as shown in the typical Clausius-Clapeyron equation: 


$$
\ln P=-\frac{\Delta H_{\mathrm{Vaq}}}{R} \frac{1}{T}+B
$$

where $\boldsymbol{P}$ is the vapor pressure of transformer oil $(\mathrm{Pa}), T$ is the testing temperature $\left({ }^{\circ} \mathrm{C}\right), \Delta H_{\operatorname{vap}}$ is the molar vaporization enthalpy $\left(\mathrm{KJ} \cdot \mathrm{mol}^{-1}\right), R$ is the molar gas constant and $B$ is the integration constant. The experiment data are initially treated and the relationship between $\ln P^{\prime}$ and $1 / T$ is displayed in Fig.5. Compared with the obtained vapor pressure data tested below $100{ }^{\circ} \mathrm{C}$, $\ln \mathrm{P}^{\prime}$ and $1 / T$ presents a obvious linear relationship when the testing temperature is above $100{ }^{\circ} \mathrm{C}$ which confirms again that the proposed vapor pressure measuring method is suitable for transformer oil at high temperature environment. When the testing temperature is below $100{ }^{\circ} \mathrm{C}$, the vapor pressure measurement is seriously influenced by testing apparatus and circumstances.

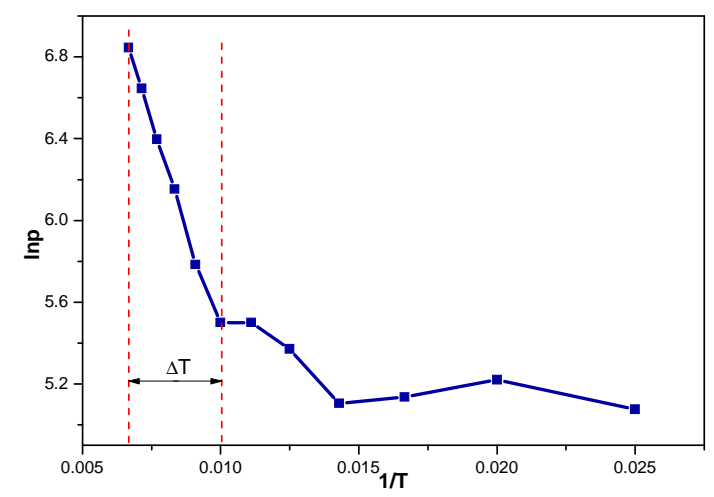

Fig.5 the treated experiment data on vapor pressure for transformer oil that tested from $30{ }^{\circ} \mathrm{C}$ to $150{ }^{\circ} \mathrm{C}$

The correlation results for the measured vapor pressure that tested in the temperature range of $\Delta T\left(100{ }^{\circ} \mathrm{C} \sim 150{ }^{\circ} \mathrm{C}\right)$ is exhibited in Fig.6. It is clear that the mentioned Clausius-Clapeyron equation describes satisfactorily the measured vapor pressures of transformer oil. Moreover, relevant fitting equation is obtained as listed below:

$$
l n P^{r}=-410.95605 \frac{1}{T}+9.57225
$$

Where the value of $-\frac{\Delta H_{\text {vag }}}{R}=-410.95605$ and the constant $\mathrm{B}$ is 9.57225 . Thus the value of $\Delta H_{v a p}=3.42 \mathrm{KJ} \cdot \mathrm{mol}^{-1}$ on transformer oil. 


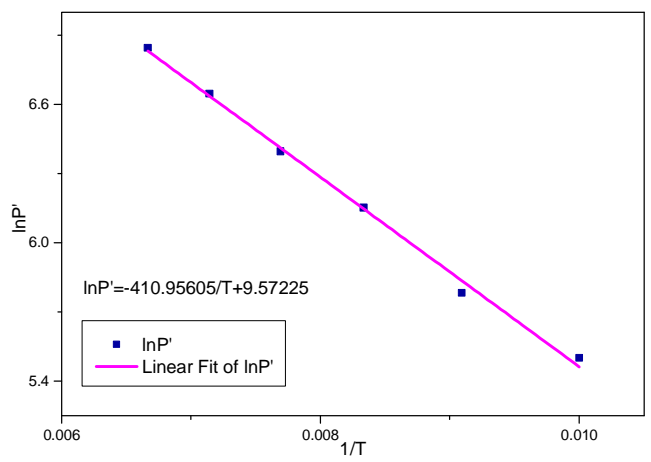

Fig. 6 the vapor pressure for transformer oil correlated by Clausius-Clapeyron equation from $100{ }^{\circ} \mathrm{C}$ to $150{ }^{\circ} \mathrm{C}$

According the above fitting equation (2), the theoretical vapor pressure of transformer oil is regressively calculated. The relating results are listed in table 2 and the comparison between the experiment data and the correlated vapor pressure of transformer oil is described in Fig.7. It can be observed that the vapor pressure is calculated from $30{ }^{\circ} \mathrm{C}$ to $180{ }^{\circ} \mathrm{C}$, corresponding to a pressure religion of $0.0161 \mathrm{~Pa}$ to $1464.3 \mathrm{~Pa}$. Obviously, the obtained theoretical vapor pressure of transformer oil fits well with the experiment data when the testing temperature above $100{ }^{\circ} \mathrm{C}$. While compared with the measured vapor pressure in the low temperature region $\left(30{ }^{\circ} \mathrm{C} \sim 100{ }^{\circ} \mathrm{C}\right)$, the calculated vapor pressure is much lower which is difficult to be tested effectively by experiment measuring method. Thus, the vapor pressure for transformer oil can be easily obtained by the mentioned experiment testing method combined with a reasonable correlation calculation from very low temperature to high temperature.

Table 2. The calculated data $\left(P^{\prime}\right)$ and experiment dada $(P)$ on vapor pressure for transformer oil

\begin{tabular}{|c|c|c|}
\hline$T /{ }^{\circ} \mathrm{C}$ & $P^{\prime} / \mathrm{Pa}$ & $P / \mathrm{Pa}$ \\
\hline 30 & 0.0161 & 170 \\
\hline 40 & 0.4958 & 160 \\
\hline 50 & 3.8695 & 185 \\
\hline 60 & 15.225 & 170 \\
\hline 70 & 40.505 & 165 \\
\hline 80 & 84.377 & 215 \\
\hline 90 & 149.32 & 245 \\
\hline 100 & 235.73 & 245 \\
\hline 110 & 342.50 & 325 \\
\hline 120 & 467.60 & 470 \\
\hline 130 & 608.53 & 600 \\
\hline 140 & 762.69 & 770 \\
\hline 150 & 927.55 & 940 \\
\hline 160 & 1100.8 & 1000 \\
\hline 170 & 1280.3 & 1300 \\
\hline 180 & 1464.3 & 1500 \\
\hline
\end{tabular}




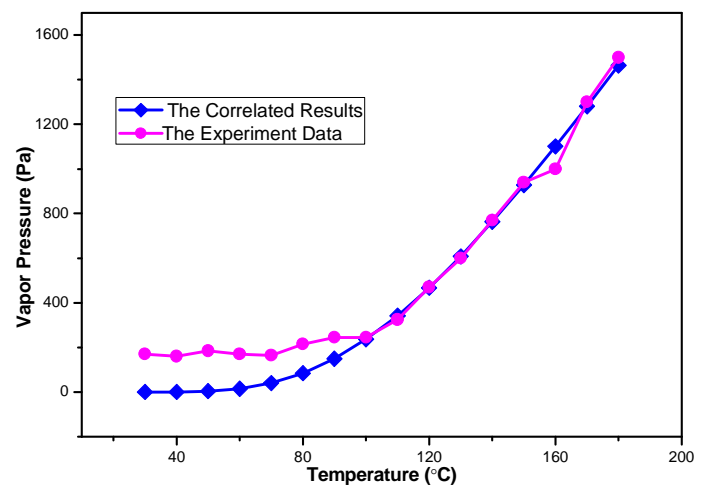

Fig.7 Comparison between the experiment data and the correlated vapor pressure of transformer oil

\section{Conclusions}

The vapor pressure of transformer oil is effectively obtained by the proposed experiment measurement combined with followed regressive calculation. It indicates that the vapor pressure of transformer oil is positively related to temperature environment which is in good agreement with the present research result. The TG and FTIR results demonstrate that the transformer oil is a typical mineral oil with complex components and no obvious aging phenomenal is observed. The experiment data is continually correlated by the typical Clausius-Clapeyron equation. Comparison between the measured data and the correlation results reveals that the tested vapor pressure is reliable when the testing temperature is above $100{ }^{\circ} \mathrm{C}$ and it shows non-negligible errors when the applied temperature is below $100{ }^{\circ} \mathrm{C}$. Based on the experiment data, the value of the molar vaporization enthalpy $\Delta H_{v a p}=3.42 \mathrm{KJ} \cdot \mathrm{mol}^{-1}$ is calculated by the correlation equation. The study results further demonstrate that the proposed vapor pressure evaluation method is suitable for transformer oil and other liquid materials with complex components especially in low temperature testing environment. This is a fundamental research which is essential to the further development of the insulation oils and the electronic industries.

\section{References}

[1] Behera P, Murugan S, Nagarajan G. Dual fuel operation of used transformer oil with acetylene in a DI diesel engine. Energ Convers Manage 2014; 87(87):840-7.

[2] Dumitran LM, Setnescu R, Notingher PV, Badicu LV, Setnescu T. Method for lifetime estimation of power transformer mineral oil. Fuel 2014; 117(1):756-62.

[3] Jada A, Chaou AA, Bertrand Y, Moreau O. Adsorption and surface properties of silica with transformer insulating oils. Fuel 2002; 81(9):1227-32.

[4] Deepa S, Sarathi R, Mishra AK. Synchronous fluorescence and excitation emission characteristics of transformer oil ageing. Talanta 2006; 70(4):811-7.

[5] Bosworth T, Setford S, Heywood R, Saini S. Pulsed amperometric detection of furan compounds in transformer oil. Analytica Chimica Acta 2001; 450(1):253-61.

[6] Ding J, Li X, Cao J, Sheng LY, Yin LZ, Xu XM. New sensor for gases dissolved in transformer oil based on solid oxide fuel cell. Sensor Actuat B Chem 2014; 202(4):232-9.

[7] Behera P, Murugan S. Combustion, performance and emission parameters of used transformer 
oil; and its diesel blends in a DI diesel engine. Fuel 2013; 104(2):147-54.

[8] Monte MJS, Santos LMNBF, Fulem M, Fonseca JMS, Sousa CAD. New static apparatus and vapor pressure of reference materials: Naphthalene, benzoic acid, benzophenone, and ferrocene. J chem Eng data 2006; 51(2):757-66.

[9] Cobranchi DP, Botelho M, Buxton LW, Buck RC, Kaiser MA. Vapor pressure determinations of 8-2 fluorortelomer alcohol and 1-H perfluorooctane by capillary gas chromatography Relative retention time versus headspace methods. J Chromatogr A 2006; 1108(2):248-51.

[10] Fulem M, Růžička K. Vapor pressure, heat capacities, and phase transitions of tetrakis(tert-butoxy)hafnium. Fluid Phase Equilibr 2011; 311(311):25-9.

[11] Price D M. Vapor pressure determination by thermogravimetry. Thermochim Acta 2001; 367(00):253-62.

[12] Sanjari E. A new simple method for accurate calculation of saturated vapor pressure. Thermochim Acta 2013; 560(10):12-6.

[13]Gharagheizi F, Eslamimanesh A, Ilani-Kashkouli P, Mohammad I AH, Richon D. QSPR molecular approach for representation/prediction of very large vapor pressure dataset. Chem Eng Sci 2012; 76(28):99-107.

[14] An H, Yang W. A new generalized correlation for accurate vapor pressure prediction. Chem Phys Lett 2012; 543:188-92.

[15] Butrow AB, Seyler RJ. Vapor pressure by DSC: extending ASTM E 1782 below 5 kPa. Thermochim Acta 2003; 402(1):145-52.

[16] Siitsman C, Kamenev I, Oja V. Vapor pressure data of nicotine, anabasine and cotinine using differential scanning calorimetry. Thermochimi Acta 2014; 595:35-42.

[17] Silva LYA, Falleiro RMM, Meirelles AJA, Krähenbühl MA. Determination of the vapor pressure of ethyl esters by Differential Scanning Calorimetry. J Chem Thermodyn 2011; 43(6):943-7.

[18] Goodrum JW, Geller DP. Rapid thermogravimetric measurements of boiling points and vapor pressure of saturated medium- and long-chain triglycerides. Bioresource Technol 2002; 84(1):75-80.

[19] Verevkin SP. Vapor pressure measurements on fluorene and methyl-fluorenes. Fluid Phase Equilibr 2004; 225(1):145-52.

[20] Mejbri K, Bellagi A. Corresponding states correlation for the saturated vapor pressure of pure fluids. Thermochim Acta 2005; 436:140-9.

[21] Forero LA, Velásquez JA. A method to estimate the Patel-Teja equation of state constants. J Chem Eng Data 2010; 55(11):5094-100.

[22] Lemmon EW, Goodwin AR. Critical Properties, Vapor pressure equation for alkanes $\mathrm{C}_{\mathrm{n}} \mathrm{H}_{2 \mathrm{n}+2}$ : normal alkanes with $n=36$ and isomers for $n=4$ through $n=9$. J Phys Chem Ref Data 2000; 29(1):1-39.

[23] Sanjari E, Honarmand M, Badihi H, Ghaheri A. An accurate generalized model for predict vapor pressure of refrigerants, Int J Refrig 2013; 36(4):1327-32.

[24] Kaanagbara L, Inyang HI, Wu J, Hilger H. Aromatic and aliphatic hydrocarbon balance in electric transformer oils. Fuel 2010; 89(10):3114-8.

[25] Fang W, Lei Q. Continuous thermodynamic correlation and calculation of vapor pressure and vapor-liquid equilibrium constant of hydrocarbon fuel fractions. Fluid Phase Equilibr 2003; 213(1):125-38. 
[26] Phang P, Dollimore D, Evans SJ. A comparative method for developing vapor pressure curves based on evaporation data obtained from a simultaneous TG-DTA unit. Thermochim Acta 2002; 392(18):119-25.

[27] Cassel B. Determining vapor pressure by pressure DSC. Perkin Elmer Therm Anal Newsl 1993; 49:2-3. 